This is the version of the article accepted for publication in Interdisciplinary Science Reviews published by Taylor \& Francis: https://doi.org/10.1080/03080188.2018.1528090

Accepted version downloaded from SOAS Research Online: http://eprints.soas.ac.uk/30032

\title{
Toward an Anthropology of Mathematizing
}

\author{
Trevor H. J. Marchand \\ Emeritus Professor of Social Anthropology, SOAS \\ tm6@soas.ac.uk
}

This essay does not offer explanations or posit conclusions. Instead, it opens a space for future investigations into the practical ways that artists and craftspeople cultivate mathematical sensibilities through their practical immersion in making and problem solving. Mathematical sensibilities, I suggest, refer to skilled kinds of perception (Grasseni 2009; Rice 2013) and heightened levels of attention and discernment regarding the qualitative properties of an object or composition, such as its shape, proportion, balance, symmetry, centredness, alignment or levelness. It also includes an "intuitive" quantitative sense of volume, mass, weight, thickness and dimension. Thus, my objective is not to describe the ways that a maker's existing knowledge and training in formal mathematics is put into practice, but rather to elucidate the ways that their practices of making produce kinds of "non-formalised", context-dependent mathematical understanding and knowledge.

\section{Craftwork and science: a personal trajectory}

In the lead essay of this special issue, Tim Ingold recounts his scholarly odyssey from the natural sciences to art, and the ways in which his anthropological explorations of art, architecture and design have reengaged him with science but, now, in more profound ways. His thinking about the person has come to share qualities with both the mycologist's thinking about fungi and the artist's practice of drawing: as opposed to being a discrete, bounded entity, the person is more productively conceived by Ingold as 'a bundle of lines, or relations, along which life is lived.'

Ingold argues that, in large part, science has come to avoid sentient involvement with the world it studies and has thereby detached the observer from the observed. That separation undermines all possibility of achieving mutual involvement in perception and action, which is the crucible from which 'all knowledge grows'. The practices of art and craft, on the other hand, display 'an opening on the world rather than an attempt at closure'. In similar spirit to the kind of anthropological practice that Ingold advocates, artists and craftspeople attend to presence, notice, respond in kind, explore in a speculative manner, and enter with things into 'a relation of correspondence'. In doing so, both anthropologists and artists 'open up to possibilities of being and knowing that might otherwise go unheeded.'

Like Ingold's odyssey, my own journey began with science. I took the science route through secondary school, followed by a college diploma in pure and 
applied sciences. ${ }^{i}$ Nearly all the elective courses I took, however, were in art history. The disciplinary combination earned me a place at McGill University's School of Architecture, which was part of the engineering faculty. Tensions simmered and banter rallied between the "pragmatic fact-crunching" engineers 
and the "artsy" architects. In comparison with their own training in concrete and steel design, the civil engineers judged our design of floor plans and facades for hypothetical buildings and our making of rendered drawings and cardboard models as "soft" and subjective, and without clear empirical criteria for testing and evaluating.

I was fortunate to secure design commissions for houses during my final years of study, and alongside this work I was also employed during the summer months as a building inspector by municipalities on the Island of Montreal. The duo of jobs allowed me to indulge my passions for design and drawing and for building and making. I learned a great deal from observing, chatting with, and sometimes debating with the contractors and tradespeople who erected the buildings I inspected and the houses I designed. To paraphrase from Ingold's essay, my onsite efforts to attend to the methods of the carpenters, masons, plumbers, electricians, plasterers and glaziers 'opened up the world to my perception'. Not only did our 'mutual involvement' inform my design and the ways that I selected and specified materials, but it also instigated a seismic shift in my direction of inquiry.

Shortly after completing my degree in architecture and a subsequent period of research with mud-brick masons in Northern Nigeria, I pursued a PhD in social anthropology. This, I reasoned, would allow me to carry out a dedicated exploration of the ways that craft skills are collectively achieved, communicated, learned, transformed and honed on site and within a community of practitioners.

The communication of skills and the coordination of skilled activity, as I quickly learned, were frequently effected entirely devoid (or with spare use) of spoken language, and so I chose to attune more carefully to the actions of the body. ${ }^{i i}$ Over a period of two decades, I carried out numerous fieldwork projects as a labourer and apprentice alongside masons in Yemen (Marchand 2001) and Mali (Marchand 2009) and then as a fine woodwork trainee at a vocational college in East London (Marchand 2007, forthcoming). By directly engaging in the working and learning environment (which Ingold defines as 'a zone of interpenetration') of my fellow builders and craftspeople, our lives became 'entangled' and, in Ingold's language, we grew and developed together in knowledge and skills. Importantly, I came to notice more fully 'the kinds of attention' that the different environments demand, and 'the responses that these demands call forth'.

\section{Anthropologist and artist}

Grounded in ethnography, my research has variously pondered the nature of motor-based concepts (2003); embodied forms of cognition and communication (2007, 2010); the brain, hand and tool nexus (2012); ageing, injury and the role of brain plasticity in craftwork (2014); and problem solving at the workbench (2016a).

More recently I had the unique occasion to participate in one-on-one fieldwork with London-based artist Andrew Omoding (Marchand 2016b). Born in 1987, Andrew left Uganda at the age of twelve to join his, until then, estranged mother in Britain. Soon after his arrival he became a selective mute. According to 
Andrew's sister, this arose from the trauma of leaving the familiar surroundings of his village and extended family and finding himself in the centre of London without close-knit community and without the skills or experience to navigate the existing support networks. He was frequently harassed and physically threatened by gangs of young people on the housing estate where he lived with his mother and sister; and, for reasons of personal security, Andrew eventually stopped jogging and using his bicycle and became increasing confined to the small flat. A few years before we met, Andrew had moved into sheltered accommodation so that he could live more independently. Conditions there progressively deteriorated, however, and at an early point during our collaboration Andrew moved back with his mother for what he hoped would be a short time.

Andrew's mother told me that her son had long found pleasure in drawing and making things. At the age of twenty-two he got support from the London-based charity ActionSpace to attend weekly full-day art sessions at their studio in the Cockpit Arts building in Bloomsbury. The ActionSpace mission is to support the development of artists with learning disabilities. The support is neither therapy nor instruction, but rather the provision of a safe and stimulating studio space with expert staff on hand and a wide range of available materials for individuals to get on with creating whatever they please.

In his application to join, Andrew declared that his interests were 'painting, sewing, laughing and being happy'. At that point, he was only just beginning to form spoken words again. In working closely with the studio convenor over the following years and socialising every Friday with ActionSpace staff and his fellow artists, Andrew's communication skills gradually progressed to making short statements and laughing boisterously; to stridently singing along with the studio radio (which, at times, mildly irritated his fellow artists); and onward to acquiring the skills and social know-how to participate in basic conversation.

Andrew's creative practices grew at an impressive rate, from pencil crayon drawings to building three-dimensional installations of structural complexity, making mobiles composed of numerous and diverse components, stitching and stuffing giant fabric figures, and creating a variety of other sculptural pieces made of found objects that he bound and wrapped in a riot of colourful fabrics, ribbons and cords. One especially interesting development in Andrew's artwork was the creation of what he called 'books'. These were patchwork quilts of fabric that he stitched together and upon which he copied out stories. Andrew could not read or write, so he dictated 'stories' to the studio convenor who printed them out in large lettering on giant sheets of paper. Andrew meticulously copied these - letter for letter, space for space - onto the fabric surface with a permanent marker pen. I have more fully described and documented this process elsewhere (Marchand 2016b, 2016c), and I made the following observation:

The stories that Andrew tells might be more accurately interpreted as assemblages of short vignettes than "stories" per se. They are not bounded by obvious beginnings or endings, and there are no recognisable threads 
linking the events and conversations described. The vignettes nevertheless possess their own whimsical, uplifting quality. They convey Andrew's innocent ambitions to have fun, and his basic desires for safety, security and protection. Recurrent themes in the vignettes revolve around home, family interactions, festive parties, holidays (often to Africa), windfalls of money, shopping, outings, singing and dancing, and food and commensality. The texts are open invitations to his audience to partake in the merriment. (2016b: 54)

Many of Andrew's works invite their audience to move beyond visual inspection and to probe the textures, folds, creases and "pockets" of the materials with fingers, to hold or cradle the objects (e.g. "Tom Baby" with bells), and even to don some items and parade about (e.g. the "Wearable Book"). Andrew's pieces powerfully express aspirations to connect with others and to make community.

In 2015, the Birmingham-based charity Craftspace commissioned me to carry out a research project with Andrew. The objectives were threefold. Firstly, the project would allow Andrew to benefit from a two-month residency at a more

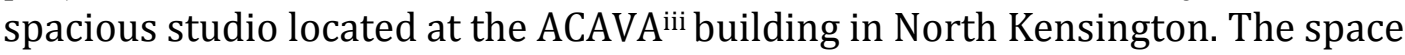
would be loaned exclusively to him each Thursday and we would work there together for the full day. On Fridays he would continue with his regular sessions at ActionSpace in Bloomsbury. The second and related objective was to provide Andrew with an opportunity to develop his making skills and to gain greater selfconfidence both as a person and an artist. The larger and dedicated space meant that he would have license to create large-scale pieces. Until now, his ambitions to do so had been curbed by having to share the ActionSpace studio with seven others.

The final objective was for me to record Andrew's processes of making and problem solving. My role would involve working closely alongside him and lending assistance when requested. In fact, Andrew was highly independent in his work, and so assistance from me (I would soon discover) entailed mainly rudimentary tasks. These included accessing the artist's materials from the storage cupboard and helping to lay them out on the work surfaces; tuning the radio to a station that played music he enjoyed; making the tea (for which Andrew never stopped to drink); holding down threads with my index finger while he stitched; passing along scissors, other tools and materials; and helping to fold the works and tidy things up at the end of the day. In generous exchange, Andrew periodically insisted on teaching me to stitch. Stitching was a skill he had learned as a boy from his aunty and grandmother in Uganda, and he derived enormous satisfaction in passing it on.

Andrew and I met for the first time in July 2015 at Cockpit Arts. In attendance were members of the ActionSpace staff and Andrew's mother, sister and her two small children. The ActionSpace support team had spotted Andrew's potential and made every effort to foster it. One of his intricate structural creations, "Ladder", was on display at the time at London's Southbank Centre as part of their Adopting Britain exhibition, iv and he had already taken part in numerous shows organised by the charity. Andrew relished the occasion to exhibit his work 
publicly. At our first meeting, we agreed to conduct the first two sessions together at Cockpit Arts. This would allow us to establish mutual trust and a productive working relationship in an environment familiar to Andrew. We then transferred to ACAVA for the remaining six sessions, which continued into late October 2015.

CraftSpace, the funder of our cooperative project, anticipated outputs from us at the end of the residency. Andrew's task was to create artworks for possible inclusion in an exhibition that the charity was planning, and my job was to author an essay for the exhibition catalogue (2016b) and produce a short film (2016c). The exhibition, titled Radical Craft and featuring the works of 34 international and British artists, ${ }^{\mathrm{v}}$ was eventually launched in March 2016 at the elegant Pallant House Gallery in Chichester. From there, the show toured to seven other venues around the U.K., finishing in Dorset in November 2017. While being hosted at the Aberystwyth Arts Centre, the exhibition included a separate gallery to display for the first time the full range of objects that Andrew had produced during our residency. A symposium was also organised at which the artist spoke about his creations. ${ }^{\text {vi }}$ This was a momentous step for Andrew.

\section{Mathematizing in making}

During our residency, one of the many things that struck me was the manner in which Andrew speedily structured his pieces and organised his canvasses of fabrics, ribbons and bobbles. I noted that his pieces were

'realised without prior studies, modelling or experimentation, and with no preconceptions of what it would ultimately be, what it would consist of, or how it might look. Like his level of literacy, the scope of his numeracy was restricted. Nevertheless, he succeeded in producing a series of objects with evenly distributed densities of detail and decoration; that had a "sense" of symmetry, balance, proportion and scale; and that combined complex shapes, three-dimensional forms and geometries. These mathematical qualities were calculated not with numbers, formulas and equations, but with Andrew's perceptual senses and with his digits, limbs and torso in motion with the tools and materials. His embodied methods of mathematizing, like his tactics for problem solving, were instantiated in the rhythms and flow of the work.' (2016b: 58)

In declaring that mathematical qualities were calculated not with numbers, formulas and equations, but with perceptual senses and the body in motion, my intent is not to neatly separate the two sets of calculating tools into a mind::body dichotomy. Indeed, I insist that numbers, formulas and equations are material devices; and that in creative activity of any kind, conceptual thinking and embodied forms of cognition are inseparable. In my introduction to Craftwork as Problem Solving, I write

'mathematicians, physicists, and philosophers engage bodily with the world in solving the problems that they encounter or set for themselves. Discussions and exchanges with colleagues serve to frame problems and to test and "craft" ideas. They use pen and paper, chalk and board, or 
keyboard and screen to objectify their thoughts in the medium of language or numbers, and to progress, refine, and shape them (Suchman and Trigg, 1993; Greeno et al., 1998). Academics might theorise space and time, the nature of things at vastly disparate scales (from universe to quark), or what it is "to be", but, ultimately, such intellectual explorations set out from, and return to, their author's sensory experiences in the world.' (2016a: 13)

These ideas about the critical importance of materials and material actions to conceptual thinking are reinforced by educationalist and mathematician Elizabeth de Freitas in her discussion of biochemist Otto Rössler's work on the so-called Rössler attractor ('an emergent geometric shape representing longterm predictions within a chaotic system'). Taking account of Rössler's reflections on his processes of invention, de Freitas notes that the scientist's 'encounter with paper and pen, the manual activity of folding and twisting [paper], combined with the visual activity of glancing and squinting [...] brought forth the new mathematical concepts' (2016a: 187).

In the remainder of this essay, I explore embodied mathematizing by reflecting upon Andrew's making of one particular object, "Flag". My aim is to present an alternative approach to thinking about mathematics, as a doing .

Mathematics is a notoriously difficult term to define. If any agreement exists between logicians, philosophers and scholars representing the various branches of mathematics, it is that no consensus on a definition has been reached. It is even debated whether mathematics is a science or a creative art (Hardy 1967: 115-116; King 1992), which in itself possesses 'supreme beauty' (Russell 1959: 60). But, evidently, the very separation of art and science into two distinct cultures is the source of that conundrum (Snow 1959; see also Carafoli, Danieli and Longo 2009).

From the time of Aristotle until the astonishing proliferation of abstract mathematical theories in the nineteenth century (e.g. Poncelet's 1822 treatise on projective geometry, Abel and Jacobi's theory of elliptic functions, and Riemann surfaces), mathematics had been largely conceived as 'the science of quantity' and as being related to the 'real world', like biology (Franklin 2014). According to Aristotelian thinking, mathematics comprises arithmetic, which studies discrete quantities, and geometry, which describes and explains continuous quantities, meaning the properties and relations of points, lines, surface and solids (Lear 1982: 186-88; White 1992).

Today, mathematics encompasses the study of quantity (arithmetic), space (geometry), structure (algebra) and change (analysis, which evolved from calculus). It is popularly conceived as paramount to most, if not all, scientific disciplines: it is formulated and practiced in the mind, communicated in formulas and equations, and - at least in its higher forms - is the preserve of specially trained (and cognitively gifted) mathematicians. Encyclopædia Britannica online defines mathematics as 
'the science of structure, order, and relation that has evolved from elemental practices of counting, measuring, and describing the shapes of objects. It deals with logical reasoning and quantitative calculation, and its development has involved an increasing degree of idealization and abstraction of its subject matter.' (Berggren et al. 2018)

In this essay, I confine my ruminations on mathematics to the arithmetic and geometry immanent in Andrew's creations and creative practices. But, notably, structure and change are also manifest in the artist's movement and his material work. For example, the 'engineering' of his sculptural installation pieces are material manifestations of what can be presumably expressed by algebraic equations; and, the changing position and velocity of Andrew's rhythmic motions and gestures are the embodiment of what might be articulated and analysed in a different manner by differential equations. I leave ideas of embodied algebra and differential change, however, to future investigation.

Like de Freitas's work, my present study pursues a materialist philosophy of mathematics (2016a; Kirby 2011). By way of example, de Freitas considers the activities of children who participate in abacus clubs and annual abacus competitions, and who speed-gesture 'with imaginary abacuses as they calculate at seemingly inhuman rates' (2016b: 651). The abacus, she notes, 'triggers the hand to think' and the 'body becomes the site' for calculating as many as '125 complicated calculations in under 12 minutes' (ibid.: 656). The body should not be 'demoted as vehicle of the mental or the ideal', she cogently argues, 'but taken to be the generative force of mathematical concepts' (ibid 658).

Though adopting a more decidedly cognitive approach, Bender and Bellen's formidable study of finger counting and numerical cognition promotes similar findings (2012). The authors propose that finger (and toe) counting, in its full array of historical and cultural variants, is a first-rate example of both embodied and distributed cognition (ibid.: 179).vii Fingers are 'naturally available and cognitively utilizable' (ibid.: 157) in that they provide 'direct perceptual feedback' (ibid.: 175) of numerical representation. I would elaborate by suggesting that direct perceptual feedback is at work in both the generator and the parser of finger-count information, albeit via different perceptual pathways: for the generator, the numerical representation is instantiated by the motorbased, proprioceptive stimuli generated by the configuration of his/her extended and folded fingers; and for the parser, numerical information is instantiated, in the first instance, by visually processing the explicit, externally available quantitative representation. But additionally, seeing the configuration of fingers will also instantiate in the parser a motor-based simulation and thus a motorbased representation, thereby achieving greater parity between the numerical representations that generator and parser entertain (Marchand 2010).

The examples of imaginary abacus using and finger counting activities are evidently mathematical, and more particularly arithmetical in that gestures and fingers are expressly used to calculate sums or communicate numerical values. Likewise, in ethnomathematic studies of basket weaving and beadwork (Gerdes $1998,2007)$, geometries are plainly materialized in the artefacts produced, 
whether in the weave itself or the decorative patterns. In studies with tailors, the subjects' situated practices of (symmetrically) aligning patterns and measuring and cutting cloth are explicitly mathematical (Lave 2010,2011), as are those of grocery shoppers comparing prices, weights and quantities in their search for best buys (Lave 1988).

At first glance, and by comparison with the abovementioned examples, Andrew's creative practices and material creations are less obviously mathematical: in his studio work, Andrew is not intentionally calculating sums, communicating numerical values, comparing quantities or taking measurements with calibrated instruments or templates. Nevertheless, his artworks emerge and grow as Andrew realizes areas, topographies, shapes and volumes and as he curates spatial, proportional, balanced and rhythmic relations between elements and layered surfaces. He does so with fine figure movements, coordinated bimanual actions, discriminating touch and vision, constricted and expansive gestures, and feet circumambulating and repeatedly carrying him in closer and away from his work - all performed while keeping pace and rhythm with the music on the radio or the tunes that he whistles. Together, the mathematical quantities and qualities of the artefacts Andrew makes, his combined perceptual activity, movements and gestures with tools and materials, and his "mathematical" representations and judgements of relations and composition are mutually constitutive and coemergent. The three also change and evolve together - dialogically - over time and with cumulative hands-on experience of making. By acknowledging that Andrew's embodied practices are generative of mathematical concepts, our collective thinking about 'what is included in doing mathematics' is enormously and progressively expanded.

In sum, I hope to contribute to recent efforts that demonstrate that the skilled practices of artists (and craftspeople) are imbued with mathematics, and more particularly a mathematics that is parsed and generated not in the mind but from the body (Marchand 2010). It thus follows that the starting point for exploring embodied mathematizing is not from the cognitive or neurosciences, psychology or formal mathematics, but rather from a phenomenological approach - 'an opening on the world' - that attends to person, materials, tools and other physical and qualitative features that make up the total environment in which activity unfolds. viii

\section{A brief background to the study of mathematics in practice}

During the past three decades, highly significant research has been carried out in the closely related fields of ethnomathematics (Ascher \& Ascher 1986; Ascher 1991, 2002; Bender \& Beller 2011; D’Ambrosio 1985; Eglash 1997; Gerdes 1999; Pickles 2009; Powell \& Frankenstein 1997), situated mathematics (Hutchins 1995; Lave 1988; Lave \& Wenger 1991; Millroy 1992; Watson \& Winbourne 2008), and embodied mathematics (Bender \& Beller 2012; Châtelet 1993, 2006; de Freitas 2016a, 2016b; de Freitas \& Sinclair 2014; Ferrara \& Nemirovsky 2005, 2009; Lakoff \& Núñez 2000; Nemirovsky 2003). Findings convincingly demonstrate that the sensing body in movement and activity calculates, quantifies, estimates, sizes-up, shapes-up and divides-up the objects, materials and world with which it is engaged. These feats are achieved without recourse to 
formal mathematical equations, theorems, or geometric principles. In short, bodily practices generate distinct kinds of mathematical sensibilities that enable people to fluidly work things out and to problem solve in the flow of work, play and everyday activity.

The term 'ethnomathematics' was first coined in 1985 by educator and mathematician Ubiratan D'Ambrosio (see also Ascher \& Ascher 1986). Despite competing definitions, it is in essence the study of the interface between culture and mathematics. Because many ethnomathematicians have concentrated on concepts of numbers and methods of basic calculation in non-literate cultures, there is underlying tendency to reify a (hierarchical) distinction between vernacular forms of mathematics and so-called "real" mathematics. By contrast, Paulus Gerdes maintained that handcrafted objects, such as the indigenous Mozambican basketry he studied, embody 'hidden' or 'frozen' mathematics, which the ethnomathematician can unlock to reveal their equivalence to classical mathematical formula or theorems (1999). While noble in its aims, this approach fails to attend to the possibility of entirely different forms of mathematics that may not in any way resemble academic mathematics. In that failure, it also forecloses opportunities to expand what is meant by mathematical knowledge.

Anthropologist Jean Lave consistently challenged the assumption that math is a 'pure universal', proposing instead that, like all else, mathematical practice is a relational, situated phenomenon (2011:19). Her ethnographic studies with West African tailors, American shoppers and Weight Watcher dieters demonstrate that math activity is complexly interwoven with social, cultural and historical relations, and therefore takes form differently in different situations. In combination, cognitive strategies, the context, relations among persons and their activities are all implicated in the success or failure of situated arithmetic. Cognition, therefore, is stretched across mind, body, activity and setting (1988).

Lave's situated and distributed approach was taken up by, among others, mathematician Wendy Millroy, who apprenticed with carpenters in Cape Town to document the mathematical ideas embedded in their everyday woodworking activities (1992). Her fellow tradesmen had minimal schooling and rudimentary numeracy skills. In difference to Lave's focus on arithmetic, Millroy's study centred on geometry and on the roles of touch and spatial visualisation in problem solving. The richness of geometry in the physical working environment, she argued, supplied the men with opportunity to develop complex geometric knowledge different to formal geometry learned in school. Mathematics is therefore characterised as dynamic and changing, and something in which people actively participate.

While being informed by a situated cognition approach, my reflections on Andrew's emergent mathematical sensibilities in art-making strive to move beyond classifying and qualifying the myriad factors that constitute mathematical learning and thinking. Grounded in the ethnography of creating "Flag", I hope to tease out the ways in which Andrew's mathematical sensibilities emerged in the coordinated activities of his sensory perceptions, gestures and tool-wielding movements in the studio. To do so, I combine the ethnography 
with observations from the related literature on mathematics and the body. The ideas I share are in no way conclusive, but rather they instigate questions and suggest starting points for further collaborative exploration with makers and scholars of other disciplines.

\section{Composing "Flag"}

Andrew arrived at the ACAVA studio twenty minutes after me. He had taken the bus by himself that morning and reported with a broad confident smile that his journey was trouble free and that he knew his way just fine. He removed his backpack and jumper and set them down on a broken swivel chair parked in a corner of the airy, light-filled room. The two of us fetched Andrew's materials from his assigned cupboard and we laid out his work-in-progress - a giant fabric "book" - on the cluster of tables at the centre of the studio. Andrew remembered exactly where he had left off with his stitching the week before and he also recalled that Isabella, the studio manager, had granted permission for him to borrow small cushions from the studio furnishings to stuff two pillowcases sewn onto the surface of his "book". The addition of the cushions would lend volume to the otherwise flat patchwork of old curtains and swatches of patterned fabric.

As Andrew took up needle and thread and resumed stitching the collage of materials, I inquired whether he had a plan for today's work. He responded matter-of-factly, 'Plan [is] stitching, then writing'. When asked whether he had a storey in mind for his book, he affirmed that he did, but offered no details. Andrew's thoughts and actions were engrossed in the sewing task at hand. Whenever the hefty white thread became tangled, he merely tucked the snag beneath a layer of fabric and proceeded to stitch. At one point, he used scissors to remove a dangling length of pencil-pleat tape from one of the old curtains. The thick cotton band had proved impenetrable for his needle and so Andrew thought it was best removed. As he bedded the cutting beneath a swatch of fabric in the middle of his composition, he announced with a grin, 'Sleep well!'

'Why didn't you just bin it?' I asked.

'Don't waste,' came Andrew's familiar mantra.

By midday Andrew proclaimed his "book" finished. The cushions, he decided, would be inserted into the pillowcases later. He expressed no interest in writing the story for the book and instead fastidiously folded the canvas edge-to-edge lengthwise, then widthwise, and over and over again until the rectangular bundle could be placed in a plastic carrier bag. Handing it over, Andrew politely asked me to put the bag away in his storage cupboard.

'Okay,' I said, 'What now?'

'Tell you in a minute,' Andrew replied.

In the same breath he reached beneath the table to retrieve one of several shopping bags bulging with supplies and he dropped it onto the worktop. Immediately he began sorting through the off-cuts of colourful translucent 
fabrics. He briskly made selections and as he did so Andrew systematically laid each rectangular piece out on the table, layering them one over the other at right angles and fastidiously aligning their straight edges in parallel with those of his work surface. His actions were performed with a certain flare, involving a flick of each lightweight gauzy fabric above the evolving composition and allowing it to float softly down to rest. Andrew then moved around the work, back and forth, fine tuning the position of the newest layer with pinched fingers and a discerning eye. In the upper layers he introduced a square of luminous saffron-coloured silk and two pieces of deep racing green satin, over which a final layer of shimmering pink transparent voile was laid. Within a matter of minutes, a sumptuous canvas had emerged, Rothko-like in its balance and composition; an architectural meshwork of translucent and solid colours, the hues of which delicately transformed in the overlays and intersections.

For philosopher-mathematician Gilles Châtelet, bodily movement was the starting point for a phenomenological analysis of diagrams and diagrammatic practices. More specifically, he considered how gestures, in their engagement with available manual technologies (e.g. straight edges, right angles, compasses, protractors, etc.) for the purposes of marking, drawing, sketching and scribbling, constitute a 'place' for mathematical invention and spatial discovery (1993).

Like Châtelet, I suggest that Andrew's gestures, actions, manipulations and movements with the fabric and with needle and thread were core to his geometric and spatial discovery. Andrew's motor activities orchestrated, and were orchestrated by, perceptual data generated by his senses of touch, kinaesthesia, proprioception and vision. Hearing, too, played a role as he danced and worked in tempo with the radio tunes and advertisement jingles. In combination, the artist's motor activities and perceptual senses actively probed for and generated phenomenological data; and in turn, that phenomenological data generated and dynamically updated Andrew's mathematical sensibilities regarding the properties of the fabric components and of the emergent composition. In manipulating the fabric pieces, Andrew discovered their individual textures, colours and opacities, as well as their densities, weights, dimensions and thicknesses. Correspondingly, he created relations and connections between them, his experiments and explorations guided by the materials. As layers accumulated, Andrew's interactive gestures detected and discerned qualities of levelness, centredness, symmetry, axiality and parallelism.

It is important to underscore that Andrew's spatial and geometric discoveries and his mathematical discernments were not happening in a mind somehow separated or distinct from his moving and sensing body. Rather, conceptualisation, movement and perception were indissolubly combined within the artist's total nervous system and generated in direct correspondence with the materials and his broader surroundings. Andrew's mathematical knowing was thereby situated and truly "embodied".

With respect to Châtelet's consideration of the role of manual technologies in combination with gestures, it must be noted that, aside from his dextrous hands and fingers, Andrew's primary tools in his "diagrammatic practices" with fabric 
were his sewing needles. For certain, these played a part in Andrew's taking measure of things. While stitching, the thickness of his needle allowed him to gauge the thickness of a fabric and the density and geometries of its weave, while the length of the needle had bearing on the spacing of his stitches and on his assessing the relative length of a seam or dimensions of a component. A clear case of gauging thickness and density occurred in the earlier-mentioned case of the pencil-pleat tape and an example of stitch spacing will be discussed later in the ethnography. I will also return to a fuller commentary on the relation between tool and body below.

Of greater importance to Andrew's mathematizing than the sewing needles were the geometries in the physical environment of the studio. The edges and rightangle corners of his flat work surface, as well as the shape and size of the room and the lines of the window mullions, doorframes, overhead track lighting and exposed steel ceiling structure all served as available geometries for calibrating his movements, aligning his gestures and attuning his visual judgements of the scale and arrangement of the fabric composition. These environmental geometries are not the "manual technologies" to which Châtelet refers, but for the studio artist they were nevertheless instrumental to his mathematical sensibilities.

In Châtelet's quest to 'awaken the physical in mathematics', he prioritized gestures and diagrams because they create open-ended possibility and 'inaugurate dynasties of problems', and are thus 'the natural accomplices of thought experiments'. In sympathetic manner, researchers in mathematics education Francesca Ferrara and Ricardo Nemirovsky acknowledged in their classroom-based studies with students that gestures with tools and materials productively extend the horizon of possibilities for mathematical imagining and experimentation (2009). In setting down the fabrics on top of the work surface, one layer over the other, the emergent composition did indeed inaugurate new problems to be solved, new possibilities to pursue (or not), and new relations of harmony and contrast, (un)balance, (dis)proportion, (a)symmetry and (mis)alignment to experiment with in both thought and action. In craftwork, a given problem can rarely, if ever, be correlated with a single possible solution. There are typically many ways to solve a problem or overcome a challenge, each one involving different investments of skill, resources and time. Like mathematical sensibilities, mathematical solutions, too, are emergent.

Elizabeth de Freitas and Nathalie Sinclair expanded Châtelet's thesis by declaring the human body a mathematical one. In their words, 'The mathematical body comes into being through actualising the virtual - through gestures, diagrams and digital networks, we become mathematics; we incorporate and are incorporated by mathematics' (2014:213). Their inclusive materialist approach collapses barriers erected between mathematics as 'pure thought' and the materiality of embodiment. Taking their cue from post-humanist theory and the work of Ingold $(2007,2011)$, the body is beneficially reconceived in terms of malleable borders and distributed networks that include prostheses, tools, materials and surfaces, and other social actors. Like the human body, mathematics, too, is recognised by the authors to be alive and changing. 
Once all the large pieces of cloth from the bag had been used, Andrew ruled that the composition was complete - at least for the time being. He studied it briefly before pulling out a white cotton sheet from a second carrier bag. It was a fitted single bed sheet that had been donated to the artist along with an assortment of other discarded linen. He decided that this needed to be placed beneath his colourful assemblage to serve as a substratum upon which all the layers could be fixed with thread. The conundrum of how to insert this new element underneath without disrupting the fragile arrangement visibly flustered Andrew. He solicited my assistance to slide the sheet below, but our several attempts failed because there were too many elements and it proved impossible to keep the light gauzy fabrics in place.

Andrew was preparing to undo the whole thing and start again when I intervened with a suggestion that we try rolling it up and then carefully unroll it over the white sheet. On later reflection, I recognised that this seemingly mundane instance of my solving a problem entailed mathematizing.ix At the time, I could foresee that if we folded the composition up lengthwise, the loose layers of fabric would topple and spill over one another as we lifted the corners; and in subsequently unfolding it on top of the white sheet, the composition would only become further dishevelled. That foresight was grounded in previous practical experimentation and experiences with comparable material circumstances. Rolling it, by contrast, took into account the discontinuous, unfixed nature of the composition's surface as well as the relative dimensions and scale of the individual elements. Carefully and tightly rolling the composition lengthwise and in parallel with the direction and edges of its individual elements significantly decreased the chances of the overall arrangement being disturbed. It also transformed the two-dimensional expanse of lightweight, guazy fabrics into a firmer, more stable cylinder, which possessed the advantages of easier handling and mobility and of being unrolled onto the white base sheet.

Andrew was happy to give it a go. Admittedly I should not have interfered with the process since, in part, my task was to observe and record Andrew's problem solving strategies as well as his creativity and playful invention. The success of our collaboration as artist and anthropologist, however, demanded teamwork and also called for empathy on occasion. The solution was a success and, in carrying out the procedure with me, Andrew learned not only a solution through hands-on experience but was engaged mathematically with the discontinuous properties of the surface; with turning that surface into a cylinder with distinct volumetric properties; and with the different mobilities of different shapes and volumes in space. When done, the artist merrily continued putting his creation together.

As Andrew realigned and readjusted the various components, he christened the new work a "flag". Indeed, it could have been the heraldic standard of some extravagant pageant.

'A flag for what?' I asked, intrigued by his classification. ${ }^{x}$ 
'For the house,' replied Andrew.

'What house?'

Andrew gestured toward the open door of the utility room that contained his storage unit and clarified, 'Table. People Eating.' He was referring to a very large canvas in progress and that was stored away for the time being. It featured knotted strands of polypropylene rope, which abstractly represented a mother, a father and children. The table (an expanse of black cotton and sage-green hessian) at which the family members came together to share a meal was, for Andrew, synonymous with "house" and the safety that a family home ideally affords (Marchand 2016b). 'House, no flag. Problem!' he added with eyebrows raised emphatically.

The dimensions of the white sheet were greater than those of the flag, and the cotton that protruded from underneath did so by roughly equal amounts on all four sides. Andrew folded the borders of white over the edges of his colourful composition to both frame and softly embrace it. He then proceeded to secure the elements with his favourite electric-blue thread, moving rapidly over the flat area and propelling the sinuous flow of the needle with the coordinated actions of his shoulder, wrist and fingers.

As previously mentioned, sewing needles were Andrew's principal tool. In all tool use, embodied forms of calculation are instantiated from the moment a craftsperson reaches for their tools. In an earlier study of the brain, hand and tool nexus, I wrote:

'Grasping a tool entails "a highly precise registration of neurological preparations for the biomechanical requirement of the task" (Wilson 1998:120). The arm moves the hand to the target guided normally by vision, and the hand must orient itself, simultaneously forming the palm, fingers and thumb in a manner appropriate for grasping, then manipulating, the particular target object. As contact is made, the fingers and palm receive haptic information and responsively adjust and fine tune the grip, and apply the necessary force to lift, then carry, manipulate or operate. Touch is both reactive and proactive, seeking tactile data that informs the shape of the grip, the application of pressure and the subsequent hand movements.' (Marchand 2012: 265)

Once in hand, an artist or craftsperson's sustained engagement with a familiar tool results in its temporary incorporation into a sense of what belongs to the user's body (Holmes and Spence 2004). This was apparent in the way that Andrew brandished his needle for long uninterrupted periods with accomplished dexterity. The sewing needle effectively supplemented and extended the physiology of Andrew's shoulder, arm, hands and fingers, and thereby became psychologically incorporated into his body. His sensory engagement with the cloth surface and his mathematical sensibilities regarding its thickness and the density of its weave were transferred from his fingertips to the tip of the needle (see Takahashi et al. 2009). 
The individual stitches on Andrew's "Flag" were widely and unevenly spaced and they sometimes zigzagged or wandered across the surface with seemingly little regard for the straight lines of the fabric edges. In effect, the stitch lines became another aesthetic layer of the composition, with their own explorative, experimental and mathematical expression. From a functional perspective, however, Andrew's aim was to secure the various elements in place by introducing stitches at critical points and junctures. In this way, too, the logic of Andrew's stitching action operated independently of the rectilinear geometries that he had created with the layered cloth. The needle in Andrew's right hand moved in tight correspondence with his gaze that roved over the topography of cloth and with the fingers of his free hand that probed for potential trouble spots, weak points and loose connections between elements. The activities of his free hand therefore not only complimented those of his dominant tool-wielding one by supplying balance to Andrew's movements and by pinching and holding the cloth as he passed the needle through, but his free fingertips also sought and generated the tactile information necessary for him to complete the task.

Although the wandering lines of thread and the inconsistent spacing between individual stitches might at first appear haphazard and unpredictable, I suggest by contrast that they be read as traces of a number of simultaneously-occurring phenomena, experiences and embodied thought processes. As tangible vestiges of Andrew's tool-wielding gestures, the wandering stitches express his playful mathematical experimentations with creating lines, patterns, diagrams and connections. They are also marks of his physical movements around the canvas and work surface, his embodied responses to the material conditions of the various fabrics and bits of haberdashery, and his calculations for holding the composition and structure of "Flag" together. In future dedicated studies, it will be important to meticulously investigate how the coordinated gestures and actions that constitute an artisan's skilled bimanual activity simultaneously produce virtual "diagrams" (in Châtelet's sense, 1993) or "traces" (in Ingold's sense, 2007:72), and thereby play a pivotal role in practitioners' situated mathematizing.

Satisfied that stability had been achieved, Andrew next combed the depths of all remaining carrier bags for lengths of brightly coloured ribbons and trimmings. To his delight he also discovered a string of pink yarn, a narrow strip of royal blue cloth, another of midnight blue with tiny white polka dots, and a swatch of pink and white gingham. These he added to the white cotton border before overlayering the whole composition with a mesh of ribbons and braided trims turquoise, scarlet, pink, mauve, green, red and gold, and cream and gold. Lengths of ribbon or trim were laid to conceal the seams between pieces of cloth while others formed independent groupings of parallel lines or grids of colour, texture and glitter. Andrew tried out numerous pieces of ribbon and if they were deemed too short, too narrow or too wide for the purpose, they were tossed back into a bag. Ones that were too long, however, were snipped to fit the task for whichever part of the flag he was working on. The next step was to secure them all with needle and thread. 
Every round of sewing began with a long strand of thread, which Andrew would use in its entirety - even when no more stitches were required. If he did cut away the excess, he inevitably tucked the unused thread into a fold of the fabric - 'Not to waste!' - and thereby preserved it as a part of the work, albeit concealed within. Folds, layers, pockets and soft textures characterised much of Andrew's artwork, for which the overriding themes were comfort, protection, safety and security. Andrew sought these things continually in his daily life as a visible minority and mentally challenged person living in sheltered accommodation in central London.

Like his earlier stitch-work, the electric blue lines that fastened the ribbons and trim skipped and roamed over the shiny satin embellishments. In only a few instances did Andrew introduce straight lines of successive stitches along a single length of ribbon. Once again, the function of the stitches was to fix the parts in place and his manual practice for doing so was tightly coupled with his visual and tactile interaction with the flag. But, equally important, the straight and zigzagging lines revealed the artist's embodied mathematical thinking with geometries and pattern. By the end of our session that day, Andrew had managed to stitch nearly all the ribbons, trim, yarn and scraps of fabric into place. He professed that he would take care of the few remaining strands during our next meeting at ACAVA in a week's time.

The following week Andrew showed up at ACAVA two days too early and Isabella, with regret, had to send him home. On the morning of our scheduled meeting, he arrived an hour late. The nature of Andrew's relationship with clock time and calendars was muddled, whereas he displayed a strong spatial awareness in his route finding abilities as well as in the proportion, symmetry and balanced arrangements of his artworks. Indeed, his creations are strongly marked by an architectural quality in terms of their layout and form, and in many cases their structure.

As usual, the session began with Andrew tuning the portable radio to a popular music station and me tinkering with the coat hanger-cum-antenna to reduce the static to an acceptable level. Together we then laid the flag out on the work surface along with Andrew's tools and supplies. He remembered immediately and with precision where he had left off, which to my mind was impressive given the large number of individual components making up the piece. He confirmed that his plan for the day was to finish stitching the flag, after which he would put buttons onto the "Table" project.

By noon he had completed "Flag" and proudly held it up before him at chest level. Andrew quickly detected, however, that a few of the ribbons were not securely attached and so he laid it back down and took up needle and thread. Before displaying it a second time, he asked me to first check for any spots that needed fixing. All looked fine to me. He held it up again with a beaming smile of satisfaction. As Andrew folded the flag up for storage, he directed my attention to the white cotton backing, telling me that he would put a book there: 'Writing on it. Next week!' 


\section{Toward an anthropology of mathematizing}

Dedicated studies of embodied mathematics could be feasibly carried out with any community or individual going about their daily activities (e.g. see Lave 1988). My reflections on Andrew's making practices, however, allowed me to broaden the scope of situated mathematizing from the narrower focus on situated calculations of sums and quantities (which, traditionally, is the subject of much research on situated mathematics) to include emergent concepts of geometry, line, surface (including continuity and discontinuity), scale and proportion. In artwork and craftwork, mathematizing in its various forms is not merely a peripheral or occasional activity, but rather mathematizing plays a key role in all of the core hands-on activities, including experimenting, exploring, design, making and problem solving with tools and materials.

Re-interrogating my field notes and recordings of Andrew making "Flag" also generated a number of questions that might guide future studies of mathematizing in artwork or equally in everyday tasks, work and play. For example, what are embodied mathematical concepts? What kinds of stimuli, data or information constitute them? How do they syntactically combine to instantiate embodied kinds of mathematical thinking, understanding and judgement - or what I have called "mathematical sensibilities"? How is embodied mathematical knowledge distinguished from formal mathematics; and what do they share? To what extent are formal mathematics derived and abstracted from embodied ways of mathematizing; and, conversely, to what extent are an individual's mathematical sensibilities informed by their schooling and their existing fluency in formal mathematics? To what extent does embodied mathematical "thinking" differ from one individual to the next, or from situation to situation? What roles do culture, social position and membership within a community of practice play in mathematical strategies and tactics in problem solving? Since embodied ways of mathematizing are emergent in everyday work and practice - often invisibly and typically below the radar of conscious awareness - why should researchers be concerned at all with understanding and explaining them?

Taking up the final question, I contend that further dedicated field research on mathematical sensibilities will reveal the extent to which, in many of our daily activities, we are mathematically engaged when sensually engaged with the world. That revelation, grounded in empirical studies, will have the power to achieve a number of important things.

To begin, it would contribute to dissolving barriers that have been historically constructed between formal mathematics and everyday mathematical sensibilities, and thereby open fields for further inquiry into the dialogic relation between them. Ethnographically-grounded documentation and anthropological exploration of emergent mathematical sensibilities in everyday practices will contribute to destabilising the notion that formal mathematics represent abstract universal truths divorced from the human condition and the messiness of everyday life. Such enduring assumptions have imputed a hierarchy between science and creative endeavours like craftwork and artwork. By revealing not only the quotidian, situated nature of maths activities, but also individual ways of 
mathematizing, future study will inevitably expose the diversity of maths and thereby vastly expand what it means to be doing maths. Sharing such findings in the public domain would contribute to combatting a general sense of alienation from (and, for many individuals, a fear of) mathematics.

More ambitiously, research into the subject could have positive impact on the design and implementation of maths curricula at primary and secondary school levels and in vocational training programmes. In the spirit of John Dewey, findings would support arguments for more creative hands-on engagement in schooling, which in turn would foster mathematical learning, thinking and problem solving that is tailored to individual (dis)ability and strengths (see also de Freitas and Sinclair 2014: 145). Such a change in curriculum would fruitfully recalibrate the balance between 'just in case learning' (which currently dominates school curricula in maths) and 'just in time learning'. The latter, importantly, cultivates skills for dynamically mathematizing and problem solving while immersed in the flux of everyday situations.

Beyond the classroom and vocational college, a deeper understanding of the nature and operations of emergent mathematical sensibilities could have weighty implications for a number of disciplines that study human performance other than craft, including sport, dance and music. Anthropological findings regarding the multi-modal nature of mathematical activities, in conjunction with related research in the cognitive and neurosciences, might also contribute to thinking within the fields of biomechanics and robotics on issues of human spatial cognition, calculation, estimation, prediction and judgement; and to approaches in rehabilitative medical practices such as physiotherapy, occupational therapy and neurosurgery that treat patients who have suffered loss or damage to such faculties as spatial awareness, orientation or the ability to engage with materials, objects and everyday tools. In short, exploration of the mathematizing body promises to advance our understanding of what it is to be human.

\section{CAPTIONS FOR FIGURES}

Figure 1: Artist Andrew Omoding layering the fabric for "Flag". Photograph by author, 2015.

Figure 2: Andrew stitching the components of "Flag" together. Photograph by author, 2015.

Figure 3: Detail of Andrew's stitchwork with electric-blue thread. Photograph by author, 2015.

Figure 4: Andrew displaying the completed "Flag". Photograph by author, 2015. 


\section{Acknowledgements}

My thanks to Willard McCarty, Elizabeth de Freitas and Roy Dilley for their generous feedback and suggestions on an earlier draft of this essay. I am indebted to Elizabeth for her inspiring presentation at the Beyond Perception symposium organised in Aberdeen in honour of Tim Ingold. It enthused me to examine embodied mathematics in a more dedicated way.

\section{References}

Ascher, M. 1991. Ethnomathematics: a multicultural view of mathematical ideas. Boca Raton: Chapman \& Hall.

2002. Mathematics Elsewhere: an exploration of ideas across cultures. Princeton: Princeton University Press.

Ascher, M. and R. Ascher 1986. 'Ethnomathematics', in History of Science. 24:125-144.

Bender, A. and S. Beller 2011. 'Numerical Cognition and Ethnomathematics', in D. Kronenfeld, G. Bennardo, V. de Munck and M. Fischer (eds.) A Companion to Cognitive Anthropology. Chichester, West Sussex: John Wiley \& Sons Ltd. Pp. 270-289.

2012. 'Nature and culture of finger counting: Diversity and representational effects of an embodied cognitive tool', in Cognition, 124(2): 156-182.

Berggren, J.L., C.G. Fraser, M. Folkerts, J.J. Gray and W.R. Knorr 2018 [1999]. 'Mathematics', in Encylopædia Britannica, online https://www.britannica.com/science/mathematics

Berti, A. and F. Frassinetti 2000. 'When Far Becomes Near: remapping of space by tool use', in Journal of Cognitive Neuroscience, 12(3): 415-420.

Carafoli, E., G.A. Danieli and G.O. Longo (eds.) 2009. The Two Cultures: shared problems. Milan: Springer-Verlag.

Châtelet, G., trans. by R. Shore and M. Zagha (1993) 2000. Figuring Space: philosophy, mathematics and physics. Dordrecht: Kluwer.

2006. 'Interlacing the Singularity, the Diagram and the Metaphor', in S. B. Duffy (ed.) Virtual Mathematics: the logic of difference. Manchester: Clinamen. Pp.31-45.

D’Ambrosio, U. 1985. 'Ethnomathematics and its Place in the History and Pedagogy of Mathematics', in For the Learning of Mathematics 5(1): 44-48.

De Freitas, E. 2016a. 'Material Encounters and Media Events: what kind of mathematics can a body do?', in Educational Studies in Mathematics, 91(2): 185-202.

2016b. Number sense and the Calculating Child: measure, multiplicity and mathematical monsters', in Discourse: studies in the cultural politics of education, 37(5): 650-661.

de Freitas, E. and N. Sinclair 2014. Mathematics and the Body: material entanglements in the classroom. Cambridge: Cambridge University Press.

Eglash, R. 1997. 'Bamana Sand Divination: recursion in ethnomathematics', in American Anthropologist 99(1): 112-122.

Farne, A., A. Iriki and E. Ladavas 2005. 'Shaping Multisensory Action Space with Tools: evidence from patience with cross-modal extinctions', in Neuropsychologia, 43(2): 238-248.

Ferrara, F. and R. Nemirovsky 2005. 'Connecting Talk, Gesture and Eye Motion for the Microanalysis of Mathematics Learning', in H. L. Chick and J. L. Vincent (eds.) Proceedings of the $29^{\text {th }}$ Conference of the International Group for the Psychology of Mathematics Education, 1: 138-142. Melbourne: P.M.E.

2009. 'Mathematical Imagination and Embodied Cognition', in EducationalStudies in Mathematics, 70: 159-174.

Fodor, J. A. 1998. Concepts: where cognitive science went wrong. Oxford: Clarendon Press.

Franklin, J. 2014. An Aristotlean Realist Philosophy of Mathematics: mathematics as the science of quantity and structure. Houndmills, Hampshire: Palgrave Macmillan.

Gerdes, P. 1998. Women, Culture and Geometry in Southern Africa. Trenton, N.J.: Africa World Press.

1999. Geometry from Africa: mathematical and educational explorations. Washington DC: The Mathematical Association of America.

2007. African Basketry: a gallery of twill-plaited designs and patterns. Morrisville, N.C.: Lulu Press. 
Grasseni, C. 2009. Developing Skill, Developing Vision: practices of locality at the foot of the Alps. Oxford: Berghahn.

Greeno, J. and Middle School Mathematics through Applications Project Group, 1998. 'The Situativity of Knowing, Learning and Research', in American Psychologist. 53(1): 5-26.

Hardy, G.H. 1967 [1940] with Foreword by C.P. Snow. A Mathematician's Apology. London: Cambridge University Press.

Holmes, N. and C. Spence 2004. 'The Body Schema and the Multisensory Representation(s) of Peripersonal Space', in Cognitive Processing, 5(2): 94-105.

Hutchins, E. 1995. Cognition in the Wild. Cambridge, MA.: MIT Press.

Ingold, T. 2007. Lines: a brief history. London: Routledge.

2011. Being Alive: essays on movement, knowledge and description. London: Routledge.

Kempson, R., W. Meyer-Viol, and D. Gabbay 2000. Dynamic Syntax: the flow of language understanding. Oxford: Wiley.

King, J.P. 1992. The Art of Mathematics. New York: Plenum Press.

Kirby, V. 2011. Quantum Anthropologies: life at large. Durham, N.C.: Duke University Press.

Kirsh, D. 2008. 'Problem Solving and Situated Cognition', in P. Robbins and M. Ayded (eds.) The Cambridge Handbook of Situated Cognition. Cambridge: Cambridge University Press. Pp. 264-306.

2011. 'How Marking in Dance Constitutes Thinking with the Body', in Versus: Quaderni di Studi Semiotica. (113-115): 179-210.

Lakoff, G. and R. Núñez 2000. Where Mathematics Comes From: how the embodied mind brings mathematics into being. New York: Basic Books.

Lave, J. 1988. Cognition in Practice. Cambridge: Cambridge University Press.

2010. 'Math Lessons from Liberia', in Anthropological Theory, 10(1-2):186-191.

2011. Apprenticeship in Critical Ethnographic Practice. Chicago: University of Chicago Press.

Lave, J., and E. Wenger 1991. Situated Learning: legitimate peripheral participation. Cambridge: Cambridge University Press.

Lear, J. 1982. 'Aristotle's Philosophy of Mathematics', in The Philosophical Review, 91(2): 161-192.

Marchand, T.H.J. 2001. Minaret Building and Apprenticeship in Yemen, Richmond, Surrey: Curzon (Routledge)

2003. 'A Possible Explanation for the Lack of Explanation; or "Why the Master Builder Can't Explain What He Knows": introducing Informational Atomism against a 'definitional' definition of concepts', in J. Pottier, A. Bicker, and P. Sillitoe (eds.), Negotiating Local knowledge: power and identity in development. London: Pluto Press, pp. 30-50.

2007. 'Vocational Migrants and a Tradition of Longing.' Traditional Dwellings and Settlements Review: Journal of the International Association for the Study of Traditional Environments, 19 (1). pp. 23-40.

2009. The Masons of Djenné. Bloomington: Indiana University Press

2010. 'Embodied Cognition and Communication: studies with British fine woodworkers.' Journal of the Royal Anthropological Institute, 16 (s1, edited by T.H.J. Marchand). pp. 100120.

2012. 'Knowledge in Hand: explorations of brain, hand and tool', in R. Fardon, T. Marchand, M. Nuttall, C. Shore, V. Strang, and C. Wilson (eds.), Handbook of Social Anthropology. London: Sage, pp. 260-269.

2014. 'Skill and Aging: Perspectives from three generations of English woodworkers.' Hallam, E. and T. Ingold (eds.), Making and Growing: Anthropological Studies of Organisms and Artefacts. Farnham, Surrey: Ashgate, pp. 183-202. (Anthropological Studies of Creativity and Perception)

2016a. 'Introduction: Craftwork as Problem Solving', in T.H.J. Marchand (ed.),Craftwork as Problem Solving: Ethnographic Studies of Design and Making. Farnham, Surrey: Ashgate, pp. 1-29.

2016b. 'Explorations in Creativity with Andrew Omoding: artist, maker and raconteur.' Radical Craft: alternative ways of making. Birmingham: Craftspace, pp. 48-59.

2016c (documentary film). The Art of Andrew Omoding. https://www.youtube.com/watch?v=zi13kf5rLpA\&t=323s

forthcoming monograph. The Pursuit of Pleasurable Work.

Millroy, W. 1992. 'An Ethnographic Study of the Mathematical Ideas of a Group of Carpenters', in Journal for Research in Mathematics Education. Monograph, 5: i-210.

Nemirovsky, R. 2003. 'Three Conjectures Concerning the Relationship between Body Activity and 
Understanding in Mathematics', in N.A. Pateman, B.J. Dougherty and J.T. Zilliox (eds.)

Proceedings of the $27^{\text {th }}$ Conference of the International Group for the Psychology of

Mathematics Education, 1: 103-135. Honolulu: PME.

Pickles, A.J. 2009. 'Part and Whole Numbers: an 'enumerative' reinterpretation of the Cambridge anthropological expedition to the Torres Straits and its subjects', in Oceania, 79(3): 293315.

Powell, A. and M. Frankenstein 1997. Ethnomathematics: challenging eurocentrism in mathematics education. Albany: State University of New York Press.

Rice, T. 2013. Hearing and the Hospital: sound, listening, knowledge and experience. Canon Pyon, Herefordshire: Sean Kingston Publishing

Russell, B. 1959. 'The Study of Mathematics', in Mysticism and Logic: and other essays. Watford, Herts.: Taylor Garnett Evans \& Co. Ltd.

Snow, C.P. (2001) [1959]. The Two Cultures. London: Cambridge University Press.

Suchman, L. and R. Trigg 1993. 'Artificial Intelligence as Craftwork', in S. Chaiklin and J. Lave (eds.) Understanding Practice: perspectives on activity and context. Cambridge: Cambridge University Press. Pp. 144-178.

Takahashi, C., J. Diedrichsen and S. Watt 2009. 'Integration of vision and haptics during tool use', in Journal of Vision 9(6):3.1-13.

Watson, A. and P. Winbourne (eds.) 2008. New Directions for Situated Cognition in Mathematics Education. New York: Springer.

White, M.J. 1992. The Continuous and the Discreet: ancient physical theories from a contemporary perspective. Oxford: Clarendon Press.

Wilson, F. 1998. The Hand: how its use shapes the brain, language and human culture. New York: Pantheon Books.

i In fact, a CEGEP (Collège d'enseignement général et professionnel) diploma.

CEGEP is a publicly funded pre-university college system unique to the Canadian province of Quebec.

ii I also learned that the linearity of spoken language fails to capture the dynamics of skilled practice, which characteristically entails the synchronous enactment of numerous cognitive, perceptual and motor activities. In short, the master masons could not effectively or efficiently explain what it is they know how to do. In my later explorations of this subject (2010), I developed a theory of motor-based concepts grounded in Fodor's theory of informational atomism (2003), and a theory of embodied communication, which builds upon the linguistic theory of Dynamic Syntax (Kempson et al. 2000)

iii ACAVA, the Association for Cultural Advancement through Visual Arts, is an educational charity providing studios for more than 500 artists in 20 buildings, mostly in London.

iv See https://www.southbankcentre.co.uk/about/press/press-

releases/southbank-centres-changing-britain-festival-presents-adopting-

britain-70

v See http://craftspace.co.uk/radicalcraft/

vi See http://www.aberystwythartscentre.co.uk/exhibitions/free-radical-craftsymposium-symposiwm-crefft-radicalaidd-am-ddim

vii With reference to Hutchins (1995), Bender and Beller define distributed cognition as the interactive processing of internally and externally represented information. The result of that interactive processing allows cognition to be offloaded into the environment through social, material, embodied and technological means, thereby alleviating the workload performed by memory retrieval. 
viii The approach I am advocating does not in any way discount valuable learning about skilled activity that can be gained from the cognitive and neurosciences or from mathematics, but rather it insists on fieldwork as the starting point and a method and analytical framework that takes stock of the total environment, as it has been defined here.

ix Thanks to Elizabeth de Freitas for this prompt.

$x$ On reflection, I recognize that my question presupposed a specific function for Andrew's flag and possibly induced the artist to create a connection between it and some other entity. On his own accord, however, he conceptualised all of the individual projects he created during our time together at ACAVA as forming part of a single installation, centered on "Table with People Eating". 